\title{
As línguas e as imagens do deslocamento em contos goeses e macaenses de língua portuguesa (1951-1975)
}

\section{The languages and displacement images in Goan and Macanese tales in Portuguese (1951-1975)}

\section{Duarte Drummond Braca*}

Resumo: Este texto pretende investigar a temática do deslocamento nas literaturas goesa e macaense de língua portuguesa, de um ponto de vista comparado, a partir de narrativas breves de Maria Elsa da Rocha, Vimala Devi, Deolinda da Conceição e Henrique Senna Fernandes. Como essas imagens da mobilidade das personagens representam ou alegorizam as próprias literaturas goesa e macaense em língua portuguesa? Será argumentado que tal funciona através da forma como a performance linguística ocorre nos textos literários abordados, ressaltando os conflitos internos e externos e permitindo começar a pensar em termos sistémicos a construção destas literaturas marginais dentro do sistema literário em língua portuguesa.

Palavras-chave: Goa, Macau, deslocamento, língua portuguesa, sistema literário

\begin{abstract}
Focusing on short narratives authored by Maria Elsa Rocha, Vimala Devi, Deolinda da Conceição and Henrique Senna Fernandes, this essay aims to investigate the theme of displacement in Goan and Macanese literatures in Portuguese in a comparative perspective. How do these images of mobility represent or allegorize the very status of Goan and Macanese literatures in Portuguese? It shall be argued that linguistic performance in the literary texts highlights both internal and external conflicts and is a basis for thinking in systemic terms the construction of these marginal literatures within the literary system of Portuguese language.
\end{abstract}

Keywords: Goa, Macau, displacement, Portuguese language, transit, literary System .

\footnotetext{
* Universidade de São Paulo (USP) / Fapesp. Texto oriundo de pesquisa de Pós-Doutoramento financiada pela FAPESP (Proc.2014/00829-8), bem como do Projeto Temático Pensando Goa, financiado pela FAPESP(Proc. 2014/15657-8).
} 


\section{- Introdução}

Goa e Macau, as duas ex-colônias portuguesas na Ásia, preservam marcas de uma ligação historicamente formada pelo sistema colonial. Todavia, o aspeto literário, em língua portuguesa, dessa relação é uma dimensão a que ainda não foi dada a devida atenção, sobretudo de um ponto de vista comparativo. Este ensaio visa propor algumas linhas de leitura para o seu entendimento no período de declínio do império português (1951-1975). Pretende-se partir da literatura goesa em língua portuguesa, quase inteiramente escrita pelas elites católicas aculturadas ao colonizador desde o século XVI, trabalhando ao mesmo tempo com a literatura macaense, voz do comunitarismo muito forte de uma sociedade mestiça luso-sínica que se desenvolveu nessa cidade chinesa.

Tendo como foco a noção e o tema do deslocamento - a viagem, o exílio ou a diáspora - descobrimos uma palataforma para pensar o algo incerto estatuto dessas literaturas, bem como a sua natureza periférica dentro do sistema literário de língua portuguesa, que se veriam figurados internamente aos textos enquanto interrogação implícita ou explícita da natureza dessas tradições literárias. Cabe-nos investigar a temática do deslocamento, bem como outras figurações do trânsito: personagens de viajantes, refugiados, exilados, por exemplo. Como essas imagens da mobilidade das personagens, enquanto questão concretizada nas obras, representa ou alegoriza as próprias literaturas goesa e macaense em língua portuguesa? Ver-se-á também, ao longo das seguintes páginas, a forma como a performance linguística nos textos literários abordados - envolvendo o confronto entre línguas, habitual nestes dois espaços plurilinguísticos - põe a nu as dependências do exterior e os conflitos internos e permite começar a pensar em termos sistémicos a construção destas literaturas. Este texto não pretende, de modo algum, esgotar este assunto, mas iniciar a sua abordagem a partir de quatro contistas do período, dois goeses e dois macaenses, escolhidos dentre um conjunto muito maior de autores que urge ler e descobrir.

\section{As línguas de / em Goa e seus retornos}

Olhando para alguns contos goeses publicados após 1961, ano da integração de Goa na União Indiana, mas ainda dentro do período colonial português como 
um todo, ressalta o tema do retorno do goês a casa. É sabido que o natural do mais pequeno estado indiano é um migrante por excelência para países acolhedores da Europa e das Américas, o que muito se intensificou com a derrocada dos impérios coloniais da Inglaterra e de Portugal. Há, assim, uma tradição de diáspora, a ser explorada na literatura goesa em língua portuguesa, que fez com que muitas das obras desses escritores tivessem sido publicadas em Portugal ${ }^{1}$.

Não é este, porém, o caso da poeta e contista Maria Elsa da Rocha² (19232005), que sempre viveu em Goa, e que dedicou sua produção ficcional à representação de camadas da população socialmente pouco visíveis, assim como a realidades linguísticas e culturais estritamente goesas ${ }^{3}$. O que aqui nos interessa é a tematização do regresso ao espaço de origem através da narrativa de um marinheiro que retorna ao torrão natal. "Telheiros baixos", conto de $1965^{4}$, consiste na pintura de todo um quadro interior e emocional, sem grande linha diegética, focando-se nas recordações e esperanças do recém-chegado que se encontra com a mãe para um Natal tipicamente goês:

Noite de Natal! Engraçado! Tão diferente de outras terras! Na sua mente cansada e ensopada de saudades da terra, as imagens quase incolores de Natais em outras terras fugiam para trás, rotas e baças, como páginas ilustradas duma revista antiga. Shi! Que doideira! Ai de coisas que ele vira! Pisou mais duro o terreno que agora descia num declive acentuado de pedras salientes que sempre serviram de degraus para gente do seu bairro... Ali, ali longe naquelas terras, os tripulantes eram como grãos de areia... Vá, ande, misture-se na multidão, velhos cartazes iluminados, prédios monstruosos, destemidos, sem ao menos arrepiar àquele frio danado... Veja mulheres brancas como cera, entrando e saindo daqueles prédios, entrando e

1 Esta questão é abundantemente desenvolvida por Joana Passos (2012).

2 Exerceu a profissão de professora primária em Goa. Colaborou na imprensa local e seu único livro, Vivências Partilhadas (2005), saíu no mesmo ano de sua morte.

3 Afirmam Hélder Garmes e Paul Melo e Castro: "A partir de uma dicção que poderíamos designar de lírico-neo-realista, Maria Elsa da Rocha sempre foi muito preocupada em registrar o cotidiano do povo goês, com quem travou conhecimento através do seu trabalho. Segundo Leopoldo da Rocha, o conjunto dos seus contos trata (muitas vezes dum ponto de vista lusófono, mas defensor duma Goa indiana) do cotidiano, dos costumes, dos desejos de uma população que nunca constituiu o foco de atenção da administração colonial portuguesa" (Garmes e Castro, 2011: 78).

4 Este conto foi identificado e transcrito por Paul Melo e Castro, que me alertou para a importância do coneito de metonymic gap para explicar os contos desta autora. 
saindo de automóveis. (...) Pronto, aquela pedra sempre foi tosca demais. Depôs a bagagem sobre o poial, limpando em seguida o suor do rosto. Sorrindo à surpresa que causaria o seu regresso, bateu à porta, devagarinho, como quem toca em um santuário. É verdade que uma vaga enorme crescia altaneira, mas ainda achou jeito para articular: Mãe, ukodd-guê, aum tô, Pêdcent. Pressentiu com o coração a bater desordenado o ranger da velha marquesa e gestos urgentes, querendo fazer luz da lamparina. "Babá!" (Rocha, 1965, p: 5)

O que interessa aqui é não apenas a tematização de um comunitarismo rural que se torna mais evidente nas épocas do ano que propiciam os regressos dos que estão fora, mas o fato de isso se traduzir num significativo momento de transformação linguística do texto. Note-se a introdução do concani (língua local de Goa) dentro do português, o que se poderia ler, a uma primeira mirada, como metonímia do confronto entre língua do colonizador e língua do colonizado, manifestando-se através da problemática do estatuto linguístico em Goa. Contudo, esta tematização da realidade multilinguística de Goa, ao ganhar uma ligação com o regresso enquanto temática narrativa, antes remete para uma literatura e um território que pensam seu próprio estatuto linguístico. A nossa ideia é que o estranhamento de uma língua local para um leitor ocidental desperta para a questão da fragilidade do português em Goa, plasmando uma interrogação do próprio texto sobre a tradição linguística (e literária) na qual ele pertence e se inscreve. O que teríamos seria assim um uso singular, ou mesmo invertido, da noção de metonymic gap (lacuna metonímica), que o teórico pós-colonial Bill Ashcroft defende. Trata-se da inserção no texto literário de certas falas numa língua local, de modo a recordar que os diálogos não se processam na língua em que o leitor os está a ler, com isso aludindo a uma assimetria de mundividências que subjaz ao discurso:

The metonymic gap is that cultural gap formed when appropriations of a colonial language insert unglossed words, phrases or passages from a first language, or concepts, allusions or references that may be unknown to the reader. Such words become synechdochic of the writer's culture (...).Thus the inserted language 'stands for' the colonized culture in a metonymic way, and its very resistance to interpretation constructs a 'gap' between the writer's culture and the colonial culture.The local writer is thus able to represent his or her world to the colonizer 
(...) in the metropolitan language, and at the same time to signal and emphasize a difference from it (Ashcroft, 2007: 123).

Todavia, isso é aqui feito com outra implicação, mais ampla, antes visando o português, desta maneira recordando que esta é uma língua pouco falada e pouco lida no território. Aqui, é a língua do colonizador a que ficou a mais, como se fosse ela a mais resistente à leitura, o que de fato é certo, tendo em conta a reduzida comunidade de leitores em língua portuguesa no contexto goês.

Encontramos uma problematização semelhante da identidade local na contista e poeta Vimala Devi (n. 1932), através da representação de figuras e de personagens que se apresentam totalmente instáveis, o que acontece, sobretudo, em seu volume de contos Monção (1962). Trata-se de uma estratégia narrativa cuja função é desestabilizar a visão regular da ordem colonial, apresentando-a de uma perspectiva que lhe é exterior, isto através de contos que representam goeses em Lisboa e portugueses em Goa. Também aqui exerce um papel significante a questão do estatuto linguístico, que é performatizado em todos esses contos. "O Futuro e o Passado" narra a história de um goês bem sucedido, que no entanto não regressa nunca a casa, ao contrário do marinheiro de Elsa da Rocha. Tendo vivido no Quênia e nos EUA, ele se encontra agora realizado profissionalmente no Brasil ${ }^{5}$. Como nos coevos contos Laços de Família (1960) de Clarice Lispector, a revisitação da vida passada e o auto-questionamento derivam de uma súbita perturbação, que culmina num regresso apenas interior. Podemos lançar mão do conceito - muito usado pela crítica em relação a Clarice - de epifania, uma vez que o que aqui acontece é muito semelhante aos momentos de revelação existencial que ocorrem naqueles contos da autora brasileira.

Ora, no caminho entre uma e outra estação do metrô carioca, o personagem goês Carlos Siqueira tem um súbito alumbramento, que desbloqueia a falta de reflexão sobre a sua própria existência até esse momento:

5 Como lembra o escritor e erudito goês Domingos Rebelo da Silva: "A demanda do Brasil é um sonho dos Goeses mais do que secular (...). Nos dois últimos séculos, alguns Goeses culturalmente bem preparados emigraram para o Brasil por conta ou iniciativa própria e ai exerceram suas atividades de médicos, arquitetos, professores, missionários, engenheiros, empresários, etc" (Silva, 2012: 7). 
Mas esse dia, quando o lotação entrou no túnel e as luzes não se acenderam, o passado veio até ele, aquele minúsculo ponto começou a crescer, a aumentar, e ocupou-Ihe todo o cérebro. Quando, de súbito, entraram na praça Princesa Isabel e viraram para Barata Ribeiro, a luz bateu-lhe de chapa nos olhos, ofuscando-o e tapando-lhe, de improviso, o futuro que procurava raivosamente para opor às recordações despertas. Então Carlos Siqueira teve uma total sensação de fracasso. Sentiu que aquele futuro, o seu futuro, o seu presente de agora, nada tinha que ver com o futuro do Carlos Siqueira que, havia mais de quarenta anos, abandonara Goa com um feixe de ambições definidas (Devi, 1962: 93).

Estamos perante uma fronteira que se abre, que é não só a do espaço interno do personagem, mas também a do espaço do conto enquanto moldura de uma situação, uma vez que a história começa com essa sensação incômoda do personagem. É o espaço na história e também o espaço da história que está sendo abertamente construído. Mas se a Índia constitui o cenário de quase todos os contos, note-se como são sublinhadas as referências geográficas brasileiras, totalmente alheias àquele país. O espaço que se transforma é obviamente uma metáfora do espaço interior, que vai sendo desvelado, simbolizado pelo ponto branco que alastra. A percepção de esgotamento do sujeito é despoletada pelo súbito sentimento de estranheza, dando origem à lembrança de que, num espaço que se torna diminuído e alheio, ele é na verdade um estrangeiro. Este é um conto que, da maneira que acabámos de ver, pergunta pelo lugar do sujeito e do espaço que ocupa.

Mas onde ver nesta epifania, um pouco menos metafísica do que a clariceana, a interrogação sobre a tradição literária goesa em língua portuguesa? A resposta passa por considerar que, tematicamente, outro tipo de clivagem de espaços é o social, induzido pela condição de burguês indiano exilado no Brasil, longe de uma Goa pobre, perdida na memória:

Tentou recordar a velha casa, as ruas esburacadas da aldeia, os manducares tristonhos, os curumbins, as canções alegres... De que the servia ser rico, de que servia ser uma pessoa importante, numa terra que não era a sua? (Devi, 1962: 94)

Com efeito, a tematização do exílio permite ver nela uma chamada de atenção para a própria condição de uma literatura goesa que se encontra em deslo- 
camento, implicando a dramática ausência no seu espaço "natural" das figuras-chave dessas literaturas. Isto é sublinhado pela biografia da autora, que esteve no Brasil no final dos anos 50, e que projeta nesta performance linguística uma reflexão, que poderíamos designar como inter-tropical, sobre Goa no Brasil. O confronto linguístico que o texto mostra negocia entre diversas formas de ser em português, como por exemplo o português do Brasil face à paisagem natural e linguística (as "canções alegres") de Goa. Daí que a via para supor uma reflexão, neste conto, sobre a língua portuguesa e a literatura nesse idioma deve passar pela forma como é aqui trabalhada a expressão oral, cuja súbita aproximação à variante brasileira serve para denunciar o sentimento de estranheza do protagonista, trazendo o leitor para a partilha dessa estranheza:

Oiça lá, meu velho, estou agora mesmo com o Leopoldino, aquele cara de Curitiba, sabe? Você si [sic] lembra daqueles terrenos para loteamento que vimos há tres meses em Jacarépaguá? [sic] (...). Pois o Leopoldino quer vender e só pode nove milhão. Si lembra das contas que fizemos, Siqueira? [...] Quer qui compre? (Devi, 1962: 94-95)

A explicitação na grafia do soundscape do português brasileiro não é inocente, transparecendo sob as expressões do português do Brasil um português mais próximo do europeu. A imitação algo canhestra pela autora só sublinha o sentimento de não-pertença a essa variante por parte do protagonista, isto no contexto de uma conversa ao telefone logo após o momento epifânico. A língua é aqui, de novo, uma metonímia da escrita literária, uma forma de inquirir por ela pois, tal como a literatura, nasce de uma falta e quer substitui-la pela enunciação de outra coisa. Afinal, qual a língua portuguesa do goês? Esta é a via pela qual se plasma a interrogação do próprio texto sobre a tradição literária a que pertence.

\section{Rompendo o comunitarismo de Macau}

Colocando em diálogo estes deslocamentos goeses com outros, olhemos ago- 
ra para a China de língua portuguesa - Macau. Deolinda da Conceição 6 é uma autora macaense cujo único livro Cheong-Sam - a Cabaia, foi publicado pela primeira vez em Lisboa em 1956 pela Livraria Francisco Franco. O conto homônimo, que abre o livro, propõe a tematização de um aspecto histórico próprio dos anos 40 e 50: a diáspora macaense em Xangai e Hong Kong, reverso da diáspora de língua portuguesa para Macau que acontecerá sobretudo nos anos 70-90. Trata-se, contudo, de uma narrativa que poderíamos designar como ingênua, na qual a diáspora causada pela guerra destrói moralmente uma família e propicia o crime e a evasão das rígidas regras morais da comunidade chinesa do território. Longe do provincianismo macaense, a esposa Chan Nui torna-se demasiado cosmopolita, exilada na China profunda, urbana e "dissoluta". Como é comum na contística tradicional, a fuga do espaço de origem cria figuras marginais que, por sua vez, se inclinam ao crime devido a essa falta original. Daí a trágica visão do marido preso, após ter assassinado a esposa "dissoluta", que se prostituía em bares de modo a custear a sobrevivência da família de exilados:

Breve partiria para o degredo, sozinho, sem o conforto de um único coração amigo, para nunca mais voltar a ver aqueles três rostinhos inocentes dos filhos, lançados na orfandade pelo destino cruel. (...) Maldita guerra! Maldita guerra, que tudo lhes levara e fizera dele um criminoso, um assassino, um pai sem coração, um homem sem raciocínio (Conceição, 1987: 22).

A consciência da fronteira marca decisivamente as personagens, uma vez que a evasão da fronteira interna com a China configura uma falta grave. A ultrapassagem de uma divisória moral ou geográfica causa a morte ou a total alienação social dos que se evadiram do espaço comunitário. Espaços trans-fronteiriços podem mobilizar encontros com o desconhecido. Os que se evadiram da comunidade recebem a marca do grotesco, como no caso do marido, que vê a cabaia da mulher por ele assassinada transformar-se em um conjunto de sombras grotescas e assustadoras. Se Macau é, como lembra Monica Simas, um lugar "conhecido pelo seu forte multiculturalismo, lugar tido por muitos como 'de passagem' e por alguns como 'de abrigo'” (Simas, 2009: 256), em “Cheong-Sam"

6 Deolinda da Conceição (Macau, 1913 - 1957) foi uma jornalista e escritora macaense de origem familiar luso-sínica. 
essa conhecida imagem da cidade Macau como local de transição ou porto de abrigo exprime o seu lado negro:

Mas, se no lar de Vong Cam tudo corria serenamente, o mesmo não acontecia no de Tai Sang Leong onde Chan Nui insistia, constantemente, com o pai por ir conhecer alguma coisa da civilização ocidental antes de tomar sobre os ombros as responsabilidades do casamento. Tinha aprendido a língua do novo mundo e admirava, pelo cinema, quanto via daquele país que parecia atraí-la com sua vida diferente, com os seus usos e costumos e com a agitação que ela verificava no seu próprio sangue. (Conceição, 1987: 26).

O trecho mostra que a origem da falta é a ocidentalização excessiva, dada pela aproximação, não da língua colonial, que é um dos idiomas da "tribo" macaista, mas da chamada "língua do novo mundo", isto é, o inglês. Chan Nui, a noiva que será morta pelo marido, mais tarde enviado para o degredo (talvez para uma outra colônia portuguesa), já tem essa potencialidade maliciosa em si ("no seu próprio sangue"), pois ela é diferente, diferença essa que a educação no Ocidente reforça e desenvolve. Este é um exemplo claro de um conto com um viés mais moral, no qual o deslocamento como um tema é indissociável da dramatização das qualidades negativas da cidade moderna: pobreza, falhanço, exclusão, aprisionamento.

Mas o tremendo comunitarismo deste conto é, de alguma forma, desconstruído por ele mesmo. Cidade totalmente dependente do exterior, algo desse deslocamento para a grande China já faz parte da natureza de Macau à partida. Afinal, os chineses que vivem em Macau são tão chineses quanto os demais, ainda que vivam em transumância por outros lugares. Não estamos aqui a falar de uma comunidade míscena, mas de chineses que falam entre si em cantonês, ainda que no conto o leiamos em português. Assim, embora o pecado original venha da aprendizagem de uma outra língua, o inglês, aquilo que precisamente os identifica como macaenses não é linguístico, mas a capacidade de migração, que revela a instabilidade de sua identidade, o que não corresponde muito bem ao registro fortemente moral do conto. A falta da personagem feminina não é o adultério, mas o esquecimento de Macau e a aceitação total de uma identidade em movimento, longe da comunidade de origem.

Henrique de Senna Fernandes (1923-2010), autor macaense que viveu em 
Portugal nos anos 50, retrata abundantemente na sua obra figuras dos macaenses exilados em Xangai ou de chineses continentais em Macau. Por exemplo, o drama do conto A-Chan, a Tancareira, publicado individualmente em 1974, e mais tarde incluído em Nam Van (1977), centra-se na personagem de uma criança enviada para Portugal, fruto de um cruzamento racial. O conto "escrito em Coimbra, em fevereiro de 1950, com saudades de Macau" (Fernandes, 1974: 20), portanto sob o signo do deslocamento, começa por afirmar a não pertença dos protagonistas à pequena cidade hoje chinesa. É, portanto, a situação contrária de Deolinda. O português, que calcorreou todo o mundo e que chega a Macau de passagem, é uma evidente alegoria do Portugal colonizador, o que é sublinhado pela sua caracterização de viés luso-tropicalista:

Manuel devassara mundos, estivera nos cruzeiros de África, familiarizara-se com os trópicos e calmarias, sequioso de aventura e da paixão do mar. Abordara a Macau, transferido para a marinha privativa da província e, durante anos se deixara seduzir pelos exotismos e sortilégios do burgo macaense. Já dava por finda a comissão, quando a guerra estalou com todo o seu cortejo de horrores (Fernandes, 1974: 9).

Macau surge como porta ou ponto de encontro entre os dois amantes, que são polos absolutos, inconciliáveis e incomunicáveis, não deixando o narrador de salientar que eles não falavam entre si, por se encontrarem isolados em mundos opostos. Trata-se de uma representação do encontro entre Ocidente e Oriente em um lugar e tempo de passagem, uma vez que Macau, por ser um território português, se manteve neutral durante a Segunda Guerra Mundial, recebendo por isso uma avalanche de refugiados, como o conto mostra. Mas trata-se de uma alegoria toldada pelo preconceito eurocêntrico e orientalista ${ }^{7}$ que conforma o conto: a mulher oriental é sempre passiva e igual a si mesma, face a um português é sempre errante, inconsciente e enganador, que acaba por Ihe roubar a criança e levá-la para a Metrópole, o que alegoriza a relação de exploração colonial. Assim, o filho deles representa Macau, mas da mesma maneira que outras figuras, tal como o intérprete que vem fazer a mediação entre pai

7 Com efeito, é desta maneira que descreve uma cena da relação: "Era feia, ignorante, açulada pela canga do rio. (...) sensibilizava-o a maneira como (...) passava os seus dedos calosos e ásperos pelos seus cabelos loiros de europeu" (Fernandes, 1974: 7). 
e mãe no clímax do roubo da criança. Esta figura poderá representar a própria literatura macaense, além de remeter, tal como o bebê, para a figura autoral, ele próprio também um mestiço.

$O$ intérprete - figura a que os textos portugueses do século $X V I$ se referiram habitualmente como "o língua" - é o símbolo da comunicabilidade e da textualidade. No texto é dito que ele "exprimiu-se arrastadamente" (Fernandes, 1974: 18). A sua fala lenta arrastada é uma espécie de mise en abyme da escrita de Senna Fernandes, também ela arrastada, no sentido de ser verbosa e prolífica, no que está algo fora do seu tempo, da ficção breve rápida e seca que caracteriza a contística em língua portuguesa dos anos 50 e 60 . É o próprio autor que o confessa, acerca do seu estilo loquaz:

Orgulho-me enternecidamente dele [Nam Van]. Por isso, os seis contos que o constituem aparecem na íntegra, tal como os escrevi para aquela edição [a primeira]. (...) Os contos foram concebidos e criados numa época distinta, com o estilo de escrita que se tinha então. Gostem ou não gostem, os leitores têm de aceitá-los com todas as suas qualidades e defeitos, tal como vieram à luz, pela primeira vez (Fernandes, 1977, s.p.).

São contos que vêm doutro tempo, tal como Macau, que também é um resquício de outro tempo, uma cidade que vive num tempo que não é nem chinês nem português. Mais uma vez, a performance linguística é o elemento que, de uma forma mais evidente, remete para a literatura, além de ser uma encenação das profundas dificuldades culturais de Macau, cuja interculturalidade oscila entre três principais esferas linguísticas: língua chinesa, portuguesa e inglesa, fenômeno para o qual Monica Simas tem alertado, desta maneira o interpretando:

A literatura de Macau parece oscilar entre um esvaziamento, já que todos os poetas podem ser incluídos em outras literaturas, como a inglesa, a portuguesa ou a chinesa, e uma hiper abrangência, se todas as línguas faladas no território vierem a constituir a sua definição (Simas, 2009: 260). 


\section{Conclusões}

A língua portuguesa, escassa e dispersa na Ásia, precisou de estratégias para se manter, devido ao confronto constante com idiomas de maior impacto, como o inglês. Nos dias de hoje, o seu futuro está longe de ser assegurado. Com efeito, as literaturas goesa e macaense têm um estatuto linguístico complexo, forçadas a lidar com o facto de o português ser, sobretudo, um significador religioso e societal, mantido por tradição familiar. Identificada com uma elite europeizada, de matriz católica, a literatura de Goa em língua portuguesa é um fenómeno singular. Já na cidade chinesa que é Macau - de que poucos são os naturais, e ainda menos os que fazem uso literário do português - os escritores que estão de passagem, ou que aí se estabelecem, também devem ser tomados como agentes dessas literaturas. Na opinião de críticos como Ana Paula Laborinho (1999: 28-32), a literatura macaense teria mesmo que contar com chineses do continente, portugueses e outros escritores residentes de modo a poder justificar a sua própria existência. Assim se entende melhor a instabilidade simbólica da língua portuguesa, fator de união não-hegemônico de algumas destas comunidades, mas também campo para uma performatização de identidades frágeis. A tematização ficcional do fenômeno linguístico torna-o explicito, e traz para a literatura esta problemática, como seu prolongamento e metonímia, de alguma forma com isso tematizando também a incerteza de sua própria sobrevivência no campo pós-colonial da chamada "Lusofonia".

Os personagens em movimento que atravessaram estas histórias constituem, segundo o pensamento de Homi Bhabha, a fronteira em movimento [shifting boundary] de Bhabha, uma vez que não são contidos pelo Heim [doméstico] das culturas nacionais. Não pertencem a lado nenhum e estão fora de, uma vez que se tratam de:

colonials, postcolonials, migrants, minorities - wandering peoples who will not be contained within the Heim of the national culture and its unisonant discourse, but 
are themselves the marks of a shifting boundary that alienates the frontiers of the modern nation (Bhabha, 1990: 315)

Assim, ficou claro há sentidos comuns e, naturalmente, ao mesmo tempo efeitos divergentes nesta comparação entre Macau e Goa. De qualquer modo, terá sido demonstrado que a permeabilidade entre estas tradições literárias não ocorre só por via do modelo colonial, mas também entre si, configurando uma outra realidade sistémica distinta das demais literaturas de expressão portuguesa. A ideia que desenvolvemos mostra que é necessário operar uma reflexão cruzada que não encerre Goa e Macau na sua uniformidade (pós)-colonial, veiculada pela sobrevivência da língua portuguesa como único termo possível para o seu relacionamento, mas que seja essencialmente um método de abertura para a pluralidade linguística e literária que é constitutiva de tais territórios.

8 Não nos foi possível consultar a tradução portuguesa deste ensaio, que deve ser procurada em "DissemiNação: O Tempo, A Narrativa e as Margens da Nação Moderna". In O Local da Cultura. Belo Horizonte: Editora da UFMG, 1998: 198-238. 


\section{Referências}

ASHCROFT, Bill. Metonymic Gap. In: ASHCROFT, B.; GRIFFITHS, G. e TIFFIN, H. (org.). Post colonial studies: the key concepts. London: Routledge, 2007, p. 122-123.

BHABHA. Homi. DissemiNation. Time, narrative and the margins of the modern nation. In: Bhabha, H. (ed.). Nation and Narration. London: Routledge 1990, p. 291-322.

CONCEIÇÃO, Deolinda da. Cheong-Sam (a cabaia). Macau: Instituto Cultural, 1987. DEVI, Vimala. Monção. Contos. Lisboa: Dédalo, 1963. FERNANDES, Henrique de Senna. A-Chan, a Tancareira. Lobito: [s.n.], 1974. . Nam Van - Contos de Macau. Instituto Cultural de Macau, 1977.

GARMES, Hélder e CASTRO, Paul Melo e. Lirismo e Conservadorismo na Arena Política: o conto 'Shivá brincando' da escritora goesa Maria Elsa da Rocha. ABRIL-Revista do Núcleo de Estudos de Literatura Portuguesa e Africana da UFF, Vol. 4, n 6, 2011, p. 77-87.

LABORINHO, Ana Paula. Por uma literatura de Macau. Anto, Revista Semestral de Cultura. Amarante: Edições do Tâmega, n. 5, 1999, p. 28-32.

PASSOS, Joana. Literatura Goesa em Português nos Séculos XIX e XX. Famalicão: Húmus, 2012.

REBELO, Domingos José Soares. Goeses no Brasil e Brasileiros em Goa: (séculos XVI/XXI)/ Goans in USA and Canada. Alcobaça: Edição do Autor, 2012.

ROCHA, Maria Elsa da. Telheiros baixos. A Vida, 23 de dezembro de 1965, p. 5.

SIMAS, Monica. Poéticas de Macau: espaços duplos, triplos e de interculturalidade. Via Atlântica - Revista da Área de Estudos Comparados de Literaturas de Língua Portuguesa da USP, São Paulo, n.ㅇ 15, 2009, p. 255-266. 